\title{
Title: TRANSPARENCY OF ASSESSMENT DECISION-MAKING WHEN STUDENTS ARE NOT MEETING REQUIRED LEVELS OF PROFICIENCY IN CLINICAL PRACTICE
}

\author{
Authors: Simon Cassidy, Michael Coffey, Fiona Murphy
}

\begin{abstract}
This paper discusses the context of assessing nursing and midwifery students who are not meeting required levels of proficiency in clinical practice. The paper then outlines an action plan protocol designed to assist supervisors and assessors examine the credibility of their assessment decisions in these circumstances.
\end{abstract}

Development of the protocol draws on a comprehensive review of evidence and original research showing the personal, professional and organizational pressures faced when a student is failing to achieve proficiency in clinical practice. The action plan protocol is suggested as one way of addressing the need to document concerns to enable students to ultimately selfregulate their learning and professional development.

\section{Introduction}

The emotional intensity of assessing pre-registration students who are not meeting required levels of proficiency in clinical practice has been debated for at least two decades yet remains a key contemporary issue for many healthcare professions. Moreover, whilst an evolving body of research recognises the importance of supportive infrastructures when supervising and assessing students in these circumstances, there are few exemplars of excellence or enabling strategies available.

The purpose of this discussion paper is to examine the utility of using a nationally ratified Action Plan Protocol (HEIW 2018) where students are not achieving practice-based proficiency commensurate with their progression on pre-registration nursing and midwifery programmes. The aim of the protocol is to provide both a pro forma for structured and effective feedback to pre-registration healthcare students who are not meeting required levels of proficiency in clinical practice and guidance to assist supervisors and assessors make effective assessment decisions in these circumstances.

\section{Background}

The complexities of responding to students who are not meeting required levels of proficiency in practice are common to many health and social care professions (Bradshaw, Pettigrew, \& Fitzpatrick 2019: Finch \& Taylor, 2013), and are issues that continue to have universal significance (Hughes, Mitchell, \& Johnston, 2016; North, Kennedy, \& Wray, 2019). 
Assessment of students in these circumstances is subjectively problematic due to assessors own ideas and opinions about a student's level of proficiency (Burden, Topping, \& O'Halloran, 2017), resource intensive (O’Driscoll, Allan, \& Smith, 2010), and emotionally overwhelming for the assessor when students may have little insight to their abilities (Larocque \& Luhanga, 2013). Such demands have the potential to significantly affect the credibility of supervisor and assessor judgements, particularly where the personal impact of making assessment decisions places a student's continuation in a healthcare programme in possible jeopardy (Black, Curzio, \& Terry, 2014).

The issue of failing to fail, where concerns about students' level of proficiency are not addressed is considered an international and multi-professional phenomenon operating across different systems of supervision and assessment and evident where the emotional impact of responding to students failing to meet required levels of proficiency is not matched by a rapid and effective support infrastructure (Bachmann, Groenvik, Hauge \& Julnes 2018; Hughes et al 2016; Luhanga et al. 2008). In the UK the term 'mentor' has been applied to nurses and midwives who support and assess pre-registration nursing and midwifery students during practice learning experiences and who are professionally accountable for assessment decisions (NMC, 2008). However, new UK Standards for student supervision and assessment (NMC 2018) accompanied by additional supporting information (NMC 2018a), establish new practice supervisor and assessor roles, with increased emphasis on collaborative working between all registered health and social care professionals in gatekeeping professional standards. These changes to student supervision and assessment arrangements from part of overall UK Nursing and Midwifery Council Standards for education (NMC 2018b) which also outline the requirements for proficiency at point of entry to the NMC register (NMC 2018c). It remains essential therefore that students are made aware of any concerns around their proficiency in practice and afforded further opportunities to achieve should they not be progressing as expected.

Such gate-keeping is especially relevant given reports of disproportionately higher numbers of students withdrawn from nursing programmes due to academic non-achievement than failing practice assessments (Hunt, McGee, Gutteridge, \& Hughes, 2012). Despite a review of the research literature about personal, professional and organisational dilemmas of assessing students who are not meeting required progression points, there are few reports of actual strategies for supervisors and assessors of students to utilise in these circumstances (Cassidy, Coffey, \& Murphy, 2017; Timmins et al., 2017). This paper presents an action plan protocol 
developed from empirical evidence as a candidate example of a strategy targeted at addressing this issue.

The protocol draws on a comprehensive review of the literature and the findings of a grounded theory study of UK nurse assessors and practice educators' experiences of assessing nursing students on the borderline of achievement of proficiency in clinical practice (Cassidy, Coffey, $\&$ Murphy, 2017). The protocol assists targeted action planning as soon as a failing assessment situation is apparent, aids analysis of student concerns, and prompts a review of key processes. A national stakeholder group of practice educators and academic staff developed the protocol by reviewing existing processes, revising the protocol content and piloting the document across a number of agreed sites in Wales UK.

This original research by Cassidy et al. (2017) showed how assessment decisions are complicated by the instability of practice settings and the subjectivity involved in making professional judgements in these circumstances. Moreover, whilst supervisors and assessors are duty-bound by their professional and pastoral obligations to nurture students' learning, they come up against a series of practical, psychological and emotional hurdles where students are not progressing as expected which can radically interrupt their assessment evaluations. The immediacy and value attached to the support supervisors and assessors receive in such circumstances, particularly from Approved Education Institution (AEI) personnel, influences how effectively these situations are managed. Drawing on sociological theories of structure and agency, the study's ultimate substantive theoretical explanation demonstrates the importance of supervisors and assessors being able to access sources of personal and professional support from a developed and trusted collegial infrastructure in order to authorize their assessment decision-making (Cassidy et al., 2017). Effective support adds to a sense of collegial identity and reassurance about the governance of nursing programmes as a whole.

Resonant with other studies, these aspects of assessment decision-making are intensified where supervisors and assessors struggle to translate the essence of their concerns into a meaningful record for others to refer to (Black, 2011; Duffy, 2006; Hunt, 2014). Such linguistic complications can mean supervisors and assessors of students assume they have recorded the detail of their concerns when this may not be the case (Allan, Smith, \& O'Driscoll, 2011; Vinales, 2015). The difficulties of specifying concerns can dissuade supervisors and assessors from giving constructive feedback to students who are not meeting expected levels of proficiency. Lack of clarity about the precise nature of supervisor and assessor anxieties about 
students may deter subsequent personnel from addressing these issues (Timmins et al., 2017). Yet there are also consequences in ignoring concerns. Apart from the prospect of a legacy of personal regret in not highlighting issues sooner, supervisors and assessors are risking those students registering as a nurse. Allowed to continue, concerns about proficiency may then be carried into employment as a new registrant with implications for patient safety and professionalism (Willis, 2015).

Consequently, the transparency of assessment decision-making is a vital consideration in circumstances where students are not meeting required standards of proficiency. These situations can be operationalised by use of the suggested protocol in this paper, which is proposed as a way forward for future discussion and debate.

\section{The Action Plan Protocol}

Although it seems little can prepare individuals for the immediate reality of responding to students who are not meeting required levels of proficiency in clinical practice, it is nevertheless vital that organizational resources are in place when it becomes clear an action plan is an appropriate response to concerns raised about a student (Hunt, McGee, Gutteridge, \& Hughes, 2016). Cassidy et al. 2017 identify the protocol as critical for a co-ordinated approach to the management of situations where students are failing to meet required proficiencies in practice, and that mechanisms exist to ensure assessment decisions stand up to scrutiny. The protocol is intended for rapid deployment where a student is not progressing as expected and a more structured response is required. Nominated supervisors and assessors, wider placement team members, as well as AEI and service provider personnel external to the placement should be involved. The protocol is available for off-the-shelf use by key stakeholders involved with the student at the time.

The protocol was developed into three constituent parts. Part A (Fig. 1) includes key questions in order to review the credibility of assessors' deliberations during a failing or borderline assessment situation. This describes an 'Assessment Footprint' of good practice. Part B (Fig. 2) outlines a suggested Action Plan Template to document failing or borderline assessment processes. Part C (Fig. 3) provides a checklist of key processes when debriefing following failing or borderline assessment situations.

\subsection{Part A: Considerations during failing assessment situations}


An Assessment footprint (Fig. 1) provides a series of questions for use by supervisors, assessors and other key personnel involved where a student is failing to meet required levels of proficiency in clinical practice. The questions within the footprint originate from the three main categories identified by our study (Cassidy et al. 2017) and are constructed to reflect issues arising for supervisors and assessors directly involved. Following a number of iterations, the questions were aligned with the major category themes of interpreting proficiency, nurturing hope and managing assessment progress (Cassidy et al. 2017). The questions are therefore embedded in this analysis of key stakeholder concerns in failing student assessment situations, and designed to trigger a review of the credibility of assessment decisions as events are unfolding. The footprint is designed as a reference for good practice as failing student assessment situations progress and is aligned to completion of Part B of the protocol - the Action Plan Template.

\section{Figure 1 here}

\subsection{Part B: Action Plan template}

The Action Plan Template (Fig. 2) was developed with reference to key aspects of the study findings and from an amalgam of existing national AEI and service provider formats. The template is designed to focus on specific student concerns and is in addition to students' overall programme record of achievement.

There is enduring evidence of the difficulties assessors have in documenting an accurate record of concerns where a student is not meeting required levels of proficiency, especially in relation to professional attitudes (Black, 2011; Duffy, 2006). Cassidy et al. (2017) highlight the difficulty of formulating assessment concerns about students into specific learning objectives. These situations are complicated by generalized descriptions of concerns inherited from previous assessors and how assumptions about what has been documented can result in inaccurate interpretations on subsequent review (Cassidy et al., 2017). In light of this, the template section is designed to facilitate agreement between relevant personnel involved on specific, measurable, attainable, relevant, time-bound (SMART) student learning objectives and review dates (Bjerke \& Renger, 2017), both as the placement is progressing and to inform future supervisors and assessors.

Copies of action plans are retained in a student's on-going record of achievement and made available in subsequent placements to enable judgements about progress. Action plans are 
normally completed electronically and added to as appropriate in light of each subsequent review meeting. All action plan documentation is signed by the student and key personnel involved and the student has access to a copy of all agreements. Students are kept fully informed regarding the ways this information is intended to be shared, used and stored (DPA 2018).

\section{Figure 2 here}

\subsection{Part C: Checklist of key processes when debriefing following failing assessment situations}

The intricacies of defining proficiency, the intensity of nurturing hopefulness and the complexity of managing assessment progress all add to the difficulties of assessment decisionmaking in situations where students are not meeting expected levels of achievement (Cassidy et al., 2017). Questions concerning the worth of investment in students who are in these circumstances can also endure after a placement has ended should relevant personnel involved not experience closure (Hunt et al., 2016). Moreover, despite the evidence that addressing concerns about a student in practice can leave a legacy of unresolved emotions (Hughes et al., 2016; Vinales, 2015), there are few reports of debriefing or case reviews taking place routinely (Hunt et al., 2016; Timmins et al., 2017). However, where there is acknowledgement of organizational resources involved in bringing key stakeholders together and assisting with the rationalization of personal and professional issues involved, the repercussions of a fail decision can be mitigated (Cassidy et al., 2017). Development of Part $C$ of the protocol was influenced by these issues. Part $\mathrm{C}$ checklist questions (Fig. 3) therefore provide a structured mechanism for debriefing and a benchmark of excellence in these situations.

\section{Figure 3 here}

Since final ratification of the protocol in July 2018 by the nationally commissioned All Wales Pre-registration Nursing and Midwifery Group, the protocol has been piloted for use by Approved Education Institutions and placement providers. Use of the document across pilot sites has generated positive feedback from clinical practice and academic staff. The protocol is embedded within new all Wales practice assessment documentation and included for discussion in supervisor and assessor preparation programmes. A mechanism has been established to monitor and evaluate sustained utilisation and effectiveness of the protocol across practice settings co-ordinated through a national practice education group. 


\section{Conclusion}

It is vital that key stakeholders responsible for supervising and assessing students in practice are suitably prepared for these roles and continue to understand their function as gatekeepers of nursing, midwifery and allied healthcare professions. Equally, more support for supervisors and assessors is required where there are doubts about a student's proficiency, especially as there are a lack of currently available strategies. In response to this, our protocol was developed. We propose further discussion on whether such protocols have utility in general.

\section{References}

Allan, H. T., Smith, P., \& O'Driscoll, M. (2011). Experiences of supernumerary status and the hidden curriculum in nursing: a new twist in the theory-practice gap? Journal of Clinical Nursing, 20(5/6), 847-855.

Bjerke, M. B., \& Renger, R. (2017). Being smart about writing SMART objectives. Evaluation and Program Planning, 61(Supplement C), 125-127. doi:https://doi.org/10.1016/j.evalprogplan.2016.12.009

Black, S. (2011). Being a mentor who fails a pre-registration nursing student in their final placement: Understanding failure ( $\mathrm{PhD})$, London South Bank University, London. http://www.rcn.org.uk/_data/assets/pdf_file/0008/458234/Black_S_PhD_Thesis_Augu st_2011.pdf

Black, S., Curzio, J., \& Terry, L. (2014). Failing a student nurse: A new horizon of moral courage. Nursing Ethics, 21(2), 224-238. doi:http://dx.doi.org/10.1177/0969733013495224

Bachmann L, Groenvik CKU, Hauge KW, Julnes S. Failing to Fail nursing students among mentors: A confirmatory factor analysis of the Failing to Fail scale. Nursing Open. 2019; 6:966-973. https://doi.org/10.1002/nop2.276

Bradshaw, C., Pettigrew, J., Fitzpatrick, M. (2019). Safety first: Factors affecting preceptor midwives experiences of competency assessment failure among midwifery students. Midwifery. 74:29-35. doi: 10.1016/j.midw.2019.03.012.

Burden, S., Topping, A. E., \& O'Halloran, C. (2017). Mentor judgements and decisionmaking in the assessment of student nurse competence in practice: A mixed-methods study. Journal of Advanced Nursing. doi:https://doi.org/10.1111/jan.13508

Cassidy, S., Coffey, M., \& Murphy, F. (2017). 'Seeking authorization': a grounded theory exploration of mentors' experiences of assessing nursing students on the borderline of achievement of competence in clinical practice. Journal of Advanced Nursing, 73(9), 2167-2178. doi:10.1111/jan.13292

DPA (2018). Data Protection Act. HMSO. London.

Duffy, K. (2006). Weighing the Balance: A grounded theory study of the factors that influence the decisions regarding the assessment of students' competence in practice. $(\mathrm{PhD})$, Glasgow Caledonian University,

Finch, J., \& Taylor, I. (2013). Failure to Fail? Practice Educators' Emotional Experiences of Assessing Failing Social Work Students. Social Work Education: The International Journal, 32(2), 244-258.

HEIW (2018). All Wales Practice Assessment Document and Ongoing Record of Achievement. 146-150. https://heiw.nhs.wales/files/once-for-wales-docs/all-walespractice-assessment-document/ 
Hughes, L. J., Mitchell, M., \& Johnston, A. N. B. (2016). 'Failure to fail' in nursing - A catch phrase or a real issue? A systematic integrative literature review. Nurse Education in Practice, 20(Supplement C), 54-63. doi:https://doi.org/10.1016/j.nepr.2016.06.009

Hunt, L. A. (2014). Failing Securely: Enabling Mentors to Fail Underperforming Student Nurses in Practical Assessments. (PhD), Birmingham, Birmingham City University.

Hunt, L. A., McGee, P., Gutteridge, R., \& Hughes, M. (2012). Assessment of student nurses in practice: A comparison of theoretical and practical assessment results in England. Nurse Education Today, 32(4), 351-355. doi:http://dx.doi.org/10.1016/j.nedt.2011.05.010

Hunt, L. A., McGee, P., Gutteridge, R., \& Hughes, M. (2016). Manipulating mentors' assessment decisions: Do underperforming student nurses use coercive strategies to influence mentors' practical assessment decisions? Nurse Education in Practice, 20, 154-162. doi:http://dx.doi.org/10.1016/j.nedt.2011.05.010

Larocque, S., \& Luhanga, F. L. (2013). Exploring the Issue of Failure to Fail in a Nursing Program. International Journal of Nursing Education Scholarship, 10(1), 1-8. doi:http://dx.doi.org/10.1515/ijnes-2012-0037

NMC. (2008). Standards to support learning and assessment in practice: NMC standards for mentors, practice teachers and teachers. from United Kingdom Nursing and Midwifery Council https://www.nmc.org.uk/globalassets/sitedocuments/standards/nmc-standardsto-support-learning-assessment.pdf

NMC. (2018a) Supporting information on standards for student supervision and assessment. from United Kingdom Nursing and Midwifery Council https://www.nmc.org.uk/supporting-information-on-standards-for-student-supervisionand-assessment/

NMC. (2018b) Standards for education. from United Kingdom Nursing and Midwifery Council https://www.nmc.org.uk/education/standards-for-education2/

NMC. (2018c). Future nurse: Standards of proficiency for registered nurses. from United Kingdom Nursing and Midwifery Council https://www.nmc.org.uk/standards/standards-for-nurses/

North, H., Kennedy, M., Wray, J. (2019). Are mentors failing to fail underperforming student nurses? An integrative literature review. British Journal of Nursing 28,4, 250-255. doi:10.12968/bjon.2019.28.4.250.

O'Driscoll, M. F., Allan, H. T., \& Smith, P. A. (2010). Still looking for leadership - Who is responsible for student nurses' learning in practice? Nurse Education Today, 30(3), 212-217.

Timmins, F., Cassidy, S., Nugent, O., Lydon, C., Part, S., Keane, L., . . Coffey, M. (2017). Reluctance to fail nursing students in practice-implications for nurse managers. Journal of Nursing Management, 25, 489-490.

Vinales, J. J. (2015). Exploring failure to fail in pre-registration nursing. British Journal of Nursing, 24(5), 284-288. doi:http://dx.doi.org/10.12968/bjon.2015.24.5.284

Willis, P. (2015). Shape of Caring: A Review of the Future Education and Training of Registered Nurses and Care Assistants. Retrieved from http://hee.nhs.uk/wpcontent/blogs.dir/321/files/2015/03/2348-Shape-of-caring-review-FINAL.pdf 